\title{
Identification of pathogenesis-related microRNAs in hepatocellular carcinoma by expression profiling
}

\author{
YUKI KATAYAMA $^{1}$, MOEGI MAEDA $^{1}$, KEN MIYAGUCHI $^{1}$, SHOTA NEMOTO $^{1}$, MAHMUT YASEN $^{1,2}$, \\ SHINJI TANAKA ${ }^{2}$, HIROSHI MIZUSHIMA ${ }^{3}$, YUTAKA FUKUOKA ${ }^{4}$, SHIGEKI ARII ${ }^{2}$ and HIROSHI TANAKA ${ }^{1}$ \\ Departments of ${ }^{1}$ Bioinformatics and ${ }^{2}$ Hepato-Biliary-Pancreatic Surgery, Graduate School, Tokyo Medical and Dental University; \\ ${ }^{3}$ Center for Public Health Informatics, National Institute of Public Health; ${ }^{4}$ Department of Biosystem Modeling, \\ Graduate School of Biomedical Science, Tokyo Medical and Dental University, Tokyo, Japan
}

Received February 13, 2012; Accepted June 1, 2012

DOI: $10.3892 / 01.2012 .810$

\begin{abstract}
Hepatocellular carcinoma (HCC) is one of the most common malignant tumors of the liver. Since postoperative recurrence and intrahepatic metastases occur frequently, the postoperative 5-year survival rate is low. To investigate the molecular mechanisms of HCC progression, mRNA as well as microRNA (miRNA) expression levels have been profiled in various studies. However, no previous study has comprehensively compared the expression of miRNAs in HCC patients with various clinical features using the tumor and surrounding non-tumor tissues and normal liver samples. In this study, we profiled the expression of miRNAs in tumor and non-tumor tissues from $40 \mathrm{HCC}$ patients with heterogeneous pathogenesis and 6 surrounding non-tumor tissues from patients with metastatic liver cancer. To identify miRNAs specific to each disease state, we comprehensively compared the expression of miRNAs in various combinations. The results indicate that the expression of many known as well as novel miRNAs was altered in patients with the hepatitis $\mathrm{C}$ virus infection compared with those with the hepatitis B virus and without any virus infection. The following miRNAs were downregulated in the tumor and non-tumor tissues, and thus could serve as novel biomarkers for chronic liver diseases: miR-18b*, miR-296-5p, miR-557, miR-581, miR-625*, miR-1228, miR-1249 and miR-2116*. Similarly, miR-129*, miR-146b-3p and miR-448 are novel candidates for HCC biomarkers regardless of virus infection.
\end{abstract}

Correspondence to: Dr Yutaka Fukuoka, Department of Biosystem Modeling, Graduate School of Biomedical Science, Tokyo Medical and Dental University, 1-5-45 Yushima, Bunkyo-ku, Tokyo 113-8510, Japan

E-mail: yu_fukuoka@ieee.org

Present address: Department of Electrical Engineering, Kogakuin University, 1-24-2 Nishi-Shinjuku, Shinjuku-ku, Tokyo 163-8677, Japan

Key words: hepatocellular carcinoma, microRNA, expression profiling, microarray

\section{Introduction}

Hepatocellular carcinoma (HCC) is one of the most common malignant tumors of the liver and the third most common cause of mortality from cancer in eastern Asia. More than $85 \%$ of HCC is caused by the hepatitis B virus (HBV) or $\mathrm{C}$ virus (HCV) infection (1-3). Other causes are exposure to aflatoxin B1 (4), vinyl chloride (5) and tobacco (6), as well as chronic ethanol ingestion (7). Many of these factors are known causes of chronic hepatitis $(\mathrm{CH})$ and liver cirrhosis, which represent a pre-neoplastic condition of HCC. HCC is often far advanced and may have multiple lesions at the time of diagnosis. Curative resection cannot be expected in cases with extrahepatic metastases. In cases without extrahepatic metastases, curative resection could potentially be performed; however, postoperative recurrence and intrahepatic metastases occur frequently, and the postoperative 5-year survival rate is reported to be $30-40 \%$ (2).

microRNAs (miRNAs) are short (19-25 nucleotides) noncoding single-stranded RNA molecules, which are cleaved from 70-100 nucleotide miRNA precursors. miRNAs regulate gene expression either at the transcriptional or translational level, based on specific binding to the complementary sequence in the coding or noncoding region of mRNA transcripts. Recent findings, based on microarray analysis of global miRNA expression profiles in cancer tissues, have revealed that miRNA profiles discriminate malignancies of the breast $(8)$, lung $(8,9)$, pancreas $(8,10)$ and liver $(11-17)$ from their counterparts.

Expression profiling of miRNA in HCC was first reported by Murakami et al (11). They comprehensively analyzed miRNA expression in HCC and non-tumor tissues and compared expression patterns in tumor and non-tumor tissues, in three differentiation levels and also between chronic hepatitis and liver cirrhosis (11). Since then, various groups have profiled miRNA expression in HCC and surrounding non-tumor tissues (12-17). Laderio et al performed miRNA profiling in HCC patients with various clinical features including normal liver samples (14). However, in their comparison, not all of the HCC samples were accompanied by their surrounding non-tumor tissues. Ura et al compared miRNA expression between HBV- and HCV-related HCC (16). 
Although they used normal liver tissue samples, all patients analyzed had the virus infection. In this way, there is no study which comprehensively compared the expression of miRNAs in HCC patients with various clinical features using tumor and surrounding non-tumor tissues. In this study, we profiled miRNA expressions in tumor and non-tumor tissues from $40 \mathrm{HCC}$ patients with heterogeneous pathogenesis. We also investigated 6 surrounding non-tumor tissues from patients with metastatic liver cancer. These were used as normal liver samples. To identify miRNAs specific to each disease state, we compared the expression of miRNAs in various combinations.

\section{Materials and methods}

Clinical specimens. Operative specimens of primary HCC and metastatic liver cancer tissues were obtained with informed consent from 40 and 6 patients, respectively, at the Department of Hepato-Biliary-Pancreatic Surgery at Tokyo Medical and Dental University Hospital between November 2005 and May 2008 (18). This research project was approved by the local ethics committee and all samples were obtained with the informed consent of the patients. The clinical findings were reviewed and analyzed from the patients' medical records, and are shown in Table I. Of the 40 patients with HCC, 12 were infected with HBV, 12 with HCV, and 16 were not infected with HBV or HCV. In addition, 6 normal liver tissue samples obtained during surgery for metastatic liver cancer originating in the colon were used as control samples. All specimens were immediately frozen in liquid nitrogen and then stored at $-80^{\circ} \mathrm{C}$ for RNA analysis.

RNA isolation. Small RNA with a miRNA-rich fraction was extracted from tissue specimens using the miRNeasy Mini kit (Qiagen, Valencia, CA, USA) according to the manufacturer's instructions. RNAs were quantified with NanoDrop ND-1000. The integrity of the obtained RNA was assessed using Agilent Bioanalyzer RNA 6000 Nano Assay (Agilent Technologies, Palo Alto, CA, USA). All samples had an RNA integrity number (RIN) $\geq 4.0$. The extracted RNAs were then analyzed by miRNA microarray using 3D-Gene (Toray Industries, Tokyo, Japan). The microarrays were scanned using GenePix 4000B.

Statistical analysis. The obtained microarray datasets were background corrected and used for statistical analyses using $\mathrm{R}$ statistical software. The Wilcoxon rank-sum test for paired data was performed to estimate the significance of miRNA gene expression differences between tumor and non-tumor tissues in 1) the 12 patients with HBV infection, 2) the 12 patients with $\mathrm{HCV}$ infection, 3) the 16 patients without virus infection, 4) the 24 patients with HBV or HCV infection, and 5) all 40 patients (see Fig. 1). In addition, an unpaired version of the Wilcoxon rank-sum test was used to compare the expression of miRNAs in the 6 normal liver samples with those in 6) the tumor and 7) non-tumor tissues in the 12 patients with HBV infection, 8) the tumor and 9) non-tumor tissues in the 12 patients with $\mathrm{HCV}$ infection, 10) the tumor and 11) non-tumor tissues in the 16 patients without virus infection, and 12) the tumor and 13) non-tumor tissues in all 40 patients (Figs. 2 and 3). MiRNAs with a fold change $>1.5$ and a $p$-value $<0.05$ were deemed as differentially expressed.
Table I. Clinical characteristics of $40 \mathrm{HCC}$ patients and 6 patients with metastatic liver cancer.

\begin{tabular}{|c|c|c|c|c|}
\hline Patient & Age & Gender & Cancer type & Virus \\
\hline L18 & 70 & M & $\mathrm{HCC}$ & HBV \\
\hline L23 & 57 & M & $\mathrm{HCC}$ & HBV \\
\hline L34 & 57 & $\mathrm{M}$ & $\mathrm{HCC}$ & HBV \\
\hline L64 & 48 & $\mathrm{~F}$ & $\mathrm{HCC}$ & HBV \\
\hline L76 & 70 & F & $\mathrm{HCC}$ & HBV \\
\hline L84 & 76 & F & $\mathrm{HCC}$ & HBV \\
\hline L85 & 51 & M & $\mathrm{HCC}$ & HBV \\
\hline L87 & 46 & $\mathrm{M}$ & $\mathrm{HCC}$ & HBV \\
\hline L116 & 68 & M & $\mathrm{HCC}$ & HBV \\
\hline L127 & 40 & M & $\mathrm{HCC}$ & HBV \\
\hline L144 & 78 & M & $\mathrm{HCC}$ & HBV \\
\hline L154 & 66 & $\mathrm{~F}$ & $\mathrm{HCC}$ & HBV \\
\hline L42 & 66 & M & $\mathrm{HCC}$ & $\mathrm{HCV}$ \\
\hline L50 & 55 & $\mathrm{~F}$ & $\mathrm{HCC}$ & $\mathrm{HCV}$ \\
\hline L63 & 68 & M & $\mathrm{HCC}$ & $\mathrm{HCV}$ \\
\hline L71 & 75 & M & $\mathrm{HCC}$ & $\mathrm{HCV}$ \\
\hline L72 & 53 & $\mathrm{M}$ & $\mathrm{HCC}$ & $\mathrm{HCV}$ \\
\hline L77 & 73 & M & $\mathrm{HCC}$ & $\mathrm{HCV}$ \\
\hline L119 & 63 & $\mathrm{~F}$ & $\mathrm{HCC}$ & $\mathrm{HCV}$ \\
\hline L120 & 71 & $\mathrm{~F}$ & $\mathrm{HCC}$ & $\mathrm{HCV}$ \\
\hline L124 & 43 & $\mathrm{~F}$ & $\mathrm{HCC}$ & $\mathrm{HCV}$ \\
\hline L130 & 63 & $\mathrm{M}$ & $\mathrm{HCC}$ & $\mathrm{HCV}$ \\
\hline L132 & 67 & $\mathrm{M}$ & $\mathrm{HCC}$ & $\mathrm{HCV}$ \\
\hline L155 & 77 & M & $\mathrm{HCC}$ & $\mathrm{HCV}$ \\
\hline L57 & 58 & M & $\mathrm{HCC}$ & - \\
\hline L58 & 73 & M & $\mathrm{HCC}$ & - \\
\hline L73 & 85 & M & $\mathrm{HCC}$ & - \\
\hline L88 & 72 & M & $\mathrm{HCC}$ & - \\
\hline L90 & 65 & M & $\mathrm{HCC}$ & - \\
\hline L97 & 80 & M & $\mathrm{HCC}$ & - \\
\hline L98 & 75 & M & $\mathrm{HCC}$ & - \\
\hline L100 & 77 & M & $\mathrm{HCC}$ & - \\
\hline L102 & 69 & M & $\mathrm{HCC}$ & - \\
\hline L104 & 64 & $\mathrm{~F}$ & $\mathrm{HCC}$ & - \\
\hline L112 & 78 & M & $\mathrm{HCC}$ & - \\
\hline L117 & 47 & $\mathrm{M}$ & $\mathrm{HCC}$ & - \\
\hline L131 & 76 & M & $\mathrm{HCC}$ & - \\
\hline L139 & 73 & $\mathrm{M}$ & $\mathrm{HCC}$ & - \\
\hline L160 & 56 & $\mathrm{M}$ & $\mathrm{HCC}$ & - \\
\hline L165 & 50 & $\mathrm{~F}$ & $\mathrm{HCC}$ & - \\
\hline C62 & 56 & $\mathrm{M}$ & Metastatic liver cancer & \\
\hline C81 & 70 & $\mathrm{M}$ & Metastatic liver cancer & \\
\hline C114 & 54 & M & Metastatic liver cancer & \\
\hline $\mathrm{C} 126$ & 59 & $\mathrm{M}$ & Metastatic liver cancer & \\
\hline C132 & 65 & $\mathrm{~F}$ & Metastatic liver cancer & \\
\hline C145 & 76 & $\mathrm{M}$ & Metastatic liver cancer & \\
\hline
\end{tabular}

HCC, hepatocellular carcinoma; HBV, hepatitis B virus; HCV, hepatitis $\mathrm{C}$ virus.

Many miRNAs have been reported to be involved in cancer. In addition to the previously mentioned miRNA profiling studies (11-17), numerous reviews and papers (19-56) 


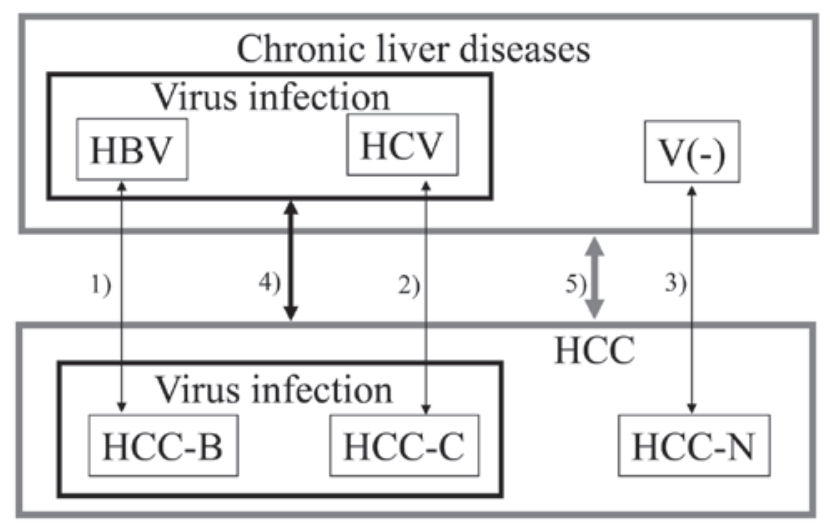

1) $\downarrow 12, \uparrow 342) \downarrow 198, \uparrow 1693) \downarrow 92, \uparrow 102 \quad 4) \downarrow 161, \uparrow 136 \quad 5) \downarrow 93, \uparrow 69$ $\underline{\text { miR-126* }} \downarrow \underline{\underline{\text { miR-512-3p }}} \downarrow \underline{\text { miR-140-3p }} \uparrow \underline{\text { miR-199a-3p }} \downarrow$ miR-199a-3p $\downarrow$ miR-24-2* $\downarrow$ miR-34* $\downarrow$ miR-1268 $\uparrow \quad \underline{\underline{m i R}-130 a} \downarrow \quad$ miR-130a $\downarrow$ $\operatorname{miR}-1297 \downarrow \operatorname{miR}-542-5 \mathrm{p} \downarrow \quad \operatorname{miR}-664 \uparrow \quad \frac{\overline{\operatorname{miR}}-1975}{\uparrow} \underline{\underline{\operatorname{miR}}-125 \mathrm{a}-5 \mathrm{p}} \downarrow$

Figure 1. Representative miRNAs detected in pairwise comparisons between tumor and non-tumor tissues. The upward and downward arrows indicate up- and downregulation, respectively, of miRNA in the tumor tissues.

were found through a literature survey on miRNA and cancer. It should be noted that we deemed a miRNA to be previously reported only when the exact name of the miRNA was found in a study. In what follows, a miRNA whose association with cancer has been previously reported is called as a previously reported miRNA. Such miRNAs may be classified into two types depending on whether they show the same or opposite tendencies to the previous reports. For certain miRNAs, it is difficult to determine whether their expressions were reportedly up- or downregulated due to inconsistent reports and lack of available information on the change direction. In the latter case, such miRNAs were described simply as cancer markers.

\section{Results}

Table II indicates the differentially expressed miRNAs between the tumor tissues in all HCC patients and the 6 normal liver samples (Combination 12). Thirty miRNAs were downregulated in the tumor tissues while 18 were upregulated. The double-underlined miRNAs have been previously reported to be involved in HCC while the miRNAs with a single underline have a reported association with other types of cancer. Most of the 18 upregulated miRNAs were known to be involved in HCC and other types of cancer. The expression of miR-15b is reported to be upregulated in $\mathrm{HCC}$ (23). Overexpression of miR-18a contributes to HCC cell proliferation in females through the targeting of the estrogen receptor (21). miR-21 is known to be highly overexpressed in HCC, and its inhibition in cultured HCC cells increases the expression of PTEN, a direct target of miR-21, as well as tumor cell proliferation, migration and invasion (20). The overexpression of miR-96 is reported in HBV-related HCC $(14,21)$. miR-222 is a HCC biomarker which is irrespective of viral association (21). miR-224 is overexpressed in HCC when compared to a benign hepatocellular tumor, hepatocellular adenoma (14), and is involved in the inhibition of apoptosis in HCC cells (21). In contrast to the upregulated
Table II. Differentially expressed miRNAs among the tumor tissues in all HCC patients and the 6 normal liver samples.

\begin{tabular}{|c|c|c|}
\hline miRNA & Fold change & P-value \\
\hline$m-2116^{*}$ & 0.048 & $<0.001$ \\
\hline$m-545^{*}$ & 0.077 & 0.012 \\
\hline$m-581$ & 0.101 & 0.004 \\
\hline$m-2114$ & 0.104 & 0.012 \\
\hline $\mathrm{m}-129 *$ & 0.127 & 0.012 \\
\hline$m-296-5 p$ & 0.161 & $<0.001$ \\
\hline$m-1267$ & 0.168 & 0.008 \\
\hline m-191* & 0.178 & 0.001 \\
\hline$m-222 *$ & 0.188 & 0.025 \\
\hline m-1249 & 0.197 & $<0.001$ \\
\hline m-18b* & 0.208 & $<0.001$ \\
\hline$m-92 a-2 *$ & 0.233 & 0.040 \\
\hline$m-625^{*}$ & 0.233 & 0.001 \\
\hline m-934 & 0.237 & 0.002 \\
\hline$m-1225-5 p$ & 0.239 & 0.026 \\
\hline m-1913 & 0.284 & 0.001 \\
\hline m-1238 & 0.286 & 0.002 \\
\hline$m-557$ & 0.288 & 0.001 \\
\hline$m-940$ & 0.292 & 0.003 \\
\hline m-1228 & 0.293 & 0.002 \\
\hline$\underline{\mathrm{m}-133 \mathrm{~b}}$ & 0.315 & 0.010 \\
\hline$\overline{\text { let- } 7 f-1} *$ & 0.324 & 0.002 \\
\hline$m-1225-3 p$ & 0.364 & 0.028 \\
\hline$m-802$ & 0.369 & 0.030 \\
\hline$m-1224-3 p$ & 0.377 & 0.012 \\
\hline $\mathrm{m}-144$ & 0.382 & 0.006 \\
\hline$\underline{\underline{m-101}}$ & 0.427 & 0.034 \\
\hline$\overline{m-486}-5 p$ & 0.551 & 0.038 \\
\hline$m-29 c$ & 0.573 & 0.047 \\
\hline$m-422 a$ & 0.576 & 0.004 \\
\hline m-1979 & 2.71 & 0.009 \\
\hline$\underline{m-140-3 p}$ & 2.83 & 0.023 \\
\hline let-7i & 3.59 & 0.017 \\
\hline$m-151-3 p$ & 3.78 & 0.005 \\
\hline$\underline{\mathrm{m}-130 \mathrm{~b}}$ & 3.80 & 0.031 \\
\hline $\mathrm{m}-425$ & 4.86 & 0.033 \\
\hline$\underline{\underline{\mathrm{m}-25}}$ & 6.55 & $<0.001$ \\
\hline$\overline{\underline{\mathrm{m}-21}}$ & 7.44 & 0.005 \\
\hline$\underline{\underline{\mathrm{m}-18}} \mathrm{a}$ & 9.05 & 0.024 \\
\hline$\underline{\underline{\mathrm{m}}-221}$ & 10.9 & 0.004 \\
\hline$\overline{m-452}$ & 11.0 & 0.017 \\
\hline$\underline{\mathrm{m}-222}$ & 14.2 & 0.026 \\
\hline$\underline{\underline{m-15 b}}$ & 18.3 & 0.016 \\
\hline$\overline{\mathrm{m}-224}$ & 82.4 & 0.006 \\
\hline$\overline{\mathrm{m}-34 \mathrm{~b}} *$ & 134 & 0.032 \\
\hline$m-374 b$ & 148 & 0.039 \\
\hline$\underline{\underline{m-96}}$ & 181 & 0.032 \\
\hline m-216a & 263 & 0.039 \\
\hline
\end{tabular}

miRNA, microRNA; HCC, hepatocellular carcinoma.

miRNAs, only two downregulated miRNAs are previously reported. miR-101 is involved in the inhibition of apoptosis 
Table III. Differentially expressed miRNAs detected in various conditions.

\begin{tabular}{|c|c|c|}
\hline Expression change & Total detected & Detected miRNAs \\
\hline Normal $\uparrow$ & 8 & $\begin{array}{l}\text { miR-18b*, miR-296-5p, miR-557, miR-581, miR-625*, miR-1228, } \\
\text { miR-1249, miR-2116* }\end{array}$ \\
\hline Tumor $\uparrow$ & 1 & $\underline{\underline{\mathrm{miR}-183}}$ \\
\hline Tumor $\downarrow$ & 5 & $\underline{\underline{\operatorname{miR}}-29 c}, \operatorname{miR}-129 *, \operatorname{miR}-146 b-3 p, \operatorname{miR}-448, \underline{\operatorname{miR}-486-5 p}$ \\
\hline $\mathrm{HCV}$ infection $\uparrow$ & 125 & 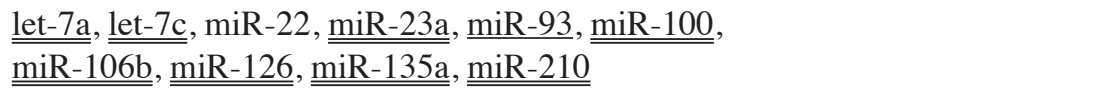 \\
\hline HCV infection $\downarrow$ & 7 & $\underline{\underline{\operatorname{miR}}-143}$, miR-548q, miR-670, miR-711, miR-718, miR-759, miR-762 \\
\hline $\mathrm{HCC}-\mathrm{C} \uparrow$ & 68 & $\begin{array}{l}\underline{\operatorname{miR}-31}, \underline{\underline{\operatorname{miR}}-96}, \operatorname{miR}-103-2^{*}, \operatorname{miR}-130 b^{*}, \underline{\underline{\operatorname{miR}}-132}, \underline{\underline{\operatorname{miR}-134}} \\
\operatorname{miR}-138, \underline{\operatorname{miR}-184}, \operatorname{miR}-301 \mathrm{a}, \underline{\operatorname{miR}-372}\end{array}$ \\
\hline $\mathrm{HCC}-\mathrm{C} \uparrow, \mathrm{V}(-) \_\mathrm{T} \downarrow$ & 24 & 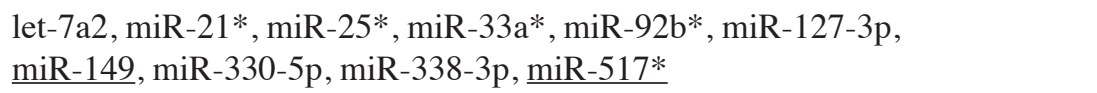 \\
\hline $\mathrm{HCV} \uparrow$ & 94 & $\underline{\underline{\underline{\operatorname{miR}}-10 \mathrm{a}}}, \underline{\underline{\underline{\operatorname{miR}-101}}}, \underline{\underline{\operatorname{miR}-197}}, \underline{\underline{\underline{\operatorname{miR}-130 \mathrm{a}-200 \mathrm{a}}}}, \underline{\underline{\underline{\operatorname{miR}-146 \mathrm{R}-200 \mathrm{~b}}}}, \underline{\underline{\operatorname{miR}-155}}, \underline{\underline{\operatorname{miR}-181 \mathrm{~b}}}$, \\
\hline $\mathrm{HCV} \uparrow, \mathrm{V}(-) \_\mathrm{N} \downarrow$ & 10 & $\begin{array}{l}\text { miR-30b*, miR-187*, miR-188-5p, miR-193b, miR-199a-5p, } \\
\text { miR-542-5p, miR-574-5p, miR-658, miR-720, miR-1287 }\end{array}$ \\
\hline $\mathrm{HCV} \downarrow$ & 7 & let-7b*, miR-139-3p, miR-220c, miR-616*, miR-708, miR-767-3p, miR-1911 \\
\hline HBV infection $\uparrow$ & 1 & $\operatorname{miR}-422 \mathrm{a}$ \\
\hline $\mathrm{HCC}-\mathrm{B} \uparrow$ & 2 & miR-605, miR-1909 \\
\hline $\mathrm{V}(-) \uparrow$ & 1 & $\operatorname{miR}-217$ \\
\hline $\mathrm{V}(-) \downarrow$ & 5 & miR-92a-2*, miR-361-3p, miR-513a-5p, miR-1234, miR-1914* \\
\hline $\mathrm{V}(-)_{-} \mathrm{T} \uparrow$ & 1 & $\operatorname{miR}-216 a$ \\
\hline $\mathrm{V}(-)_{-} \mathrm{T} \downarrow$ & 10 & $\begin{array}{l}\text { miR-133a, miR-199b-5p, miR-338-5p, miR-491-3p, miR-509-3-5p, } \\
\text { miR-543, miR-627, miR-887, miR-921, miR-1247 }\end{array}$ \\
\hline $\mathrm{V}(-) \_\mathrm{N} \downarrow$ & 6 & miR-664, miR-671-3p, miR-1246, miR-1268, miR-1280, miR-1978 \\
\hline
\end{tabular}

Normal $\uparrow$ denotes downregulation in the tumor and non-tumor tissues when compared with normal liver. Tumor $\uparrow$ denotes upregulation in the tumor tissues only and no alteration in the non-tumor tissues. HCV infection $\uparrow$ denotes upregulation in the tumor and non-tumor tissues in patients with $\mathrm{HCV}$ infection while $\mathrm{HCV} \uparrow$ denotes upregulation in the non-tumor tissue of such patients. V(-) denotes patients without virus infection. HCC, hepatocellular carcinoma; HBV, hepatitis B virus; HCV, hepatitis C virus. The double-underlined miRNAs have been previously reported to be involved in HCC while the miRNAs with a single underline have a reported association with other types of cancer.
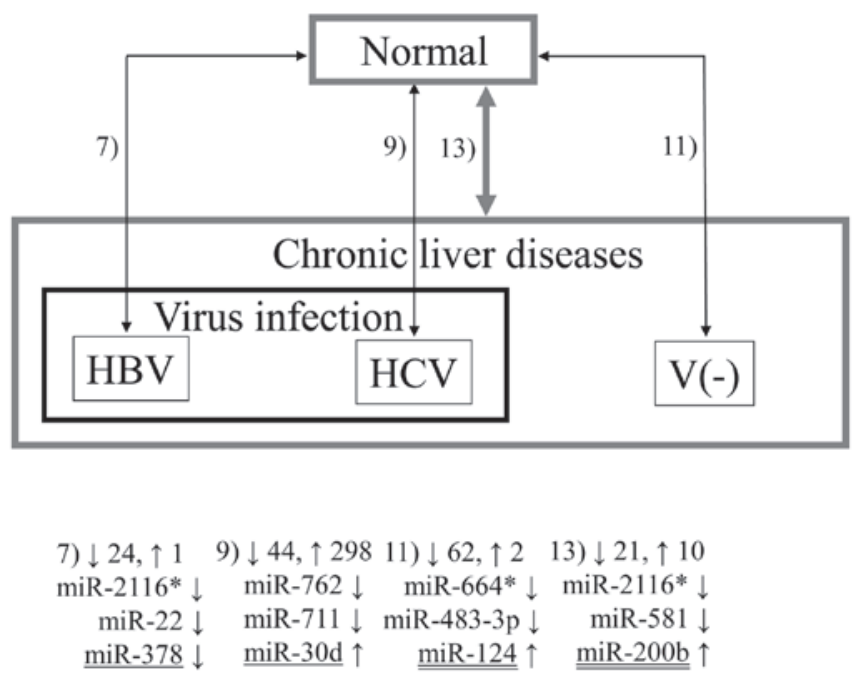

Figure 2. Representative miRNAs detected in comparisons of the normal liver samples with non-tumor tissues. The upward and downward arrows indicate up- and downregulation, respectively, of miRNA in the non-tumor tissues. Combinations 7, 9, 11 and 13 are explained in Materials and methods.
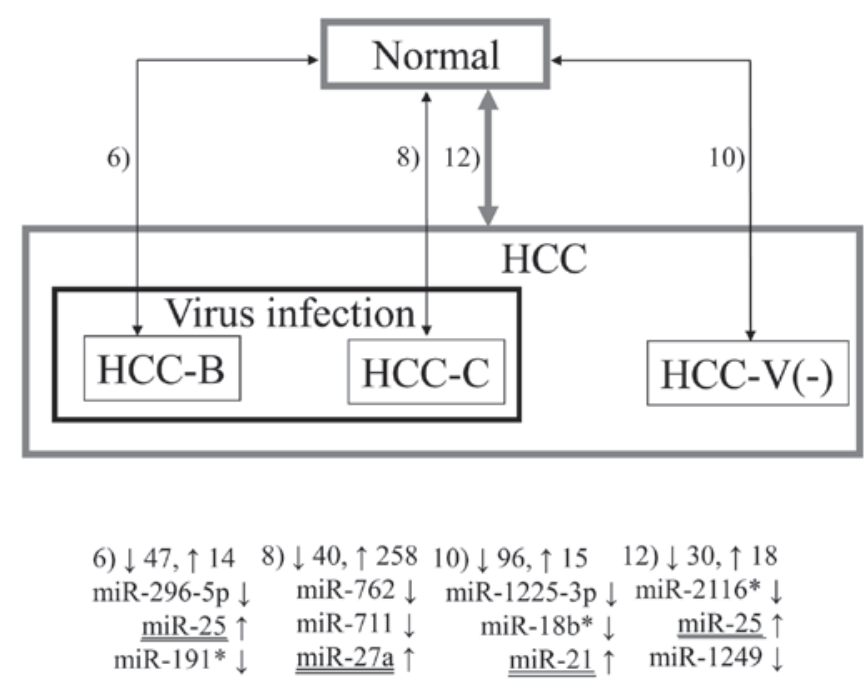

Figure 3. Representative miRNAs detected in comparisons of the normal liver samples with tumor tissues. The upward and downward arrows indicate up- and downregulation, respectively, of miRNA in the tumor tissues. Combinations 6, 8, 10 and 12 are explained in Materials and methods. 
and its downregulation contributes to the spread of HCC (21).

Figs. 1-3 summarize the results from all 13 combinations described in Materials and methods. The numbers 1-13 denote the aforementioned combinations. The numbers beside the upwards and downwards-pointing arrows indicate the numbers of up- and downregulated miRNAs, respectively. Three representative miRNAs in each combination are also shown. Here, 'representative' means the miRNAs with the first and second lowest p-values and the previously reported miRNA with the lowest p-value among the previously reported ones (underlined in the figures in the same way as in Table II). If the previously reported miRNA was the same as either of the first two, the miRNA with the third lowest p-value is shown in the figure. In all five combinations comparing tumor and non-tumor tissues, previously reported miRNAs demonstrated the lowest p-values (Fig. 1). Notably, the three representative miRNAs for HCC with HBV infection (Combination 1) and HCC without virus infection (Combination 3) do not include any miRNA with previous association with HCC. Conversely, many novel miRNAs as well as previously reported miRNAs were detected by the unpaired Wilcoxon rank-sum test (Figs. 2 and 3).

If a miRNA is deemed to be upregulated in the tumor tissue when comparing tumor and non-tumor tissue, and also downregulated in the non-tumor tissues when comparing normal liver samples and non-tumor tissues, these results indicate that the miRNA was actually downregulated in the non-tumor tissue and thus it was detected as upregulated in the tumor when comparing the tumor and non-tumor tissues. To investigate such detailed changes, we compared lists of the differentially expressed miRNAs from the 13 combinations. Table III shows the results. For example, Normal $\uparrow$ denotes that these miRNAs were downregulated in the tumor and non-tumor tissues compared with the normal liver. Similarly, Tumor $\uparrow$ denotes that these miRNAs were upregulated in the tumor tissues only and their expression was not altered in the non-tumor tissues. HCV infection $\uparrow$ indicates upregulation in the tumor and non-tumor tissues in patients with $\mathrm{HCV}$ infection while $\mathrm{HCV} \uparrow$ represents upregulation in the non-tumor tissue of the patients with $\mathrm{HCV}$. V(-) denotes patients without virus infection. The expression levels of many miRNAs were altered in HCV-positive patients whereas a relatively small number of miRNAs were detected in patients with HBV and without virus infection.

\section{Discussion}

In this study, miRNA expression was profiled in tumor and surrounding non-tumor tissues from $40 \mathrm{HCC}$ patients with various clinical features. We first performed pairwise comparisons of miRNA expression between the tumor and non-tumor tissues. We also profiled miRNA expression in non-tumor tissue samples from 6 patients with metastatic liver cancer. These non-tumor samples were considered as normal liver and compared with the results from each of the tumor and non-tumor tissues in patients with HBV and HCV or without infection. These comprehensive comparisons provided valuable insight into the alteration of miRNAs in the tumor and non-tumor tissues. For example, when a ratio of 1.5 is obtained from a comparison of the miRNA expression level in tumor and non-tumor tissues, it cannot be proven whether the miRNA expression was increased in the tumor tissue or decreased in the non-tumor tissue, since both cases will produce the same results. Employing normal liver samples enables this distinction.

As shown in Fig. 2, miR-30d, miR-124, miR-200b and miR-378 demonstrated significant changes in expression in the non-tumor tissues in HCC patients compared with normal liver samples in Combinations 7, 9, 11 and 13. In all combinations except 9 , only a few previously detected miRNAs were observed: let-7e, let-7f, miR-98 and miR-144. Notably, none of them demonstrated the same tendency observed in previous studies. In Combination 9, more than 80 of the 342 miRNAs detected were previously reported, and 21 and 24 of them demonstrated the same and opposite tendencies observed in previous reports, respectively. These results suggest that these miRNAs may play a role in the very early stages of carcinogenesis in HCC and some may have different roles in HCC and chronic liver diseases.

As shown in Table III, miR-2116* was significantly downregulated in $\mathrm{HCC}$ as well as the surrounding non-tumor tissues compared with the normal liver samples in all possible combinations; thus, miR-2116* may have some influence upon carcinogenesis of HCC. Although this miRNA has no previously reported correlation with cancer, its predicted target genes involve genes associated with cancer. The top four predicted targets with the strongest prediction scores (57) were ZDHHC11, MTCH2, DIRC2 and PEA15 (as of January 2012 according to www.microrna.org). The gene copy number of $\mathrm{ZDHHCl1}$ was altered in nearly half of the patients with non-small cell lung cancer (58) and bladder cancer (59). $\mathrm{MTCH} 2$ is a gene exhibiting highly restricted levels of gene expression variation in tumor tissues compared to non-malignant tissues (60). Bodmer et al identified DIRC2 as a familial renal cell carcinoma-associated gene (61). The expression level of PEA15 was used for grading the malignancy of astrocytic tumors (62). These facts indicate that the predicted targets play roles in cancer. The expression of miR-2116* was altered in the non-tumor tissues when compared to the normal liver samples, and accordingly, as discussed earlier, this miRNA may also play a role in the early stages of carcinogenesis. Other miRNAs which were consistently downregulated in the tumor and nontumor tissues are miR-18b*, miR-296-5p, miR-557, miR-581, miR-625*, miR-1228 and miR-1249. Similar to miR-2116*, the predicted target genes of miR-1249 involved numerous genes whose association with cancer has been reported.

The results strongly suggest that the above miRNAs are novel biomarker candidates for chronic liver diseases. Some are novel biomarker candidates for HCC irrespective of virus infection and HCC with HCV, as shown in Table III. In this way, through miRNA expression profiling, we identified various pathogenesis-related miRNAs which may be used as biomarkers for a specific disease state, although further investigation is required.

\section{Acknowledgements}

This study was funded by the Scientific Research Grant (No. 20510184), Science and Technology Promotion 
Adjustment Expenses (No. 08005234), and the Integrated Database Project, from the Ministry of Education, Culture, Sports, Science and Technology of Japan.

\section{References}

1. El-Serag HB and Rudolph KL: Hepatocellular carcinoma: epidemiology and molecular carcinogenesis. Gastroenterology 132 2557-2576, 2007.

2. Blum H: Hepatocellular carcinoma: therapy and prevention. World J Gastroenterol 11: 7391-7400, 2005.

3. Cramp M: HBV + HCV = HCC? Gut 45: 168-169, 1999

4. Soini Y, Chia SC, Bennett WP, et al: An aflatoxin-associated mutational hotspot at codon 249 in the p53 tumor suppressor gene occurs in hepatocellular carcinomas from Mexico. Carcinogenesis 17: 1007-1012, 1996.

5. Boffetta P, Matisane L, Mundt KA and Dell LD: Meta-analysis of studies of occupational exposure to vinyl chloride in relation to cancer mortality. Scand J Work Environ Health 29: 220-229, 2003.

6. Tsukuma H, Hiyama T, Oshima A, et al: A case-control study of hepatocellular carcinoma in Osaka, Japan. Int J Cancer 45: 231-236, 1995.

7. Donato F, Tagger A, Gelatti U, et al: Alcohol and hepatocellular carcinoma: the effect of lifetime intake and hepatitis virus infections in men and women. Am J Epidemiol 155: 323-333, 2002.

8. Volinia S, Calin GA, Liu CG, et al: A microRNA expression signature of human solid tumors defines cancer gene targets. Proc Natl Acad Sci USA 103: 2257-2261, 2006.

9. Yanaihara N, Caplen N, Bowman E, et al: Unique micro RNA molecular profiles in lung cancer diagnosis and prognosis. Cancer Cell 9: 189-198, 2006.

10. Lee EJ, Gusev Y, Jiang J, et al: Expression profiling identifies microRNA signature in pancreatic cancer. Int J Cancer 120 1046-1054, 2007.

11. Murakami Y, Yasuda T, Saigo K, et al: Comprehensive analysis of microRNA expression patterns in hepatocellular carcinoma and non-tumorous tissues. Oncogene 25: 2537-2545, 2006.

12. Budhu A, Jia HL, Forgues M, et al: Identification of metastasisrelated microRNAs in hepatocellular carcinoma. Hepatology 47 897-907, 2008.

13. Varnhort H, Drebber U, Schulze F, et al: MicroRNA gene expression profile of hepatitis $\mathrm{C}$ virus-associated hepatocellular carcinoma. Hepatology 47: 1223-1232, 2008.

14. Laderio Y, Couchy G, Balabaud C, et al: MicroRNA profiling in hepatocellular tumor is associated with clinical features and oncogene/tumor suppressors gene mutations. Hepatology 47 1955-1963, 2008.

15. Li W, Xie L, He X, et al: Diagnostic and prognositic implications of microRNAs in human hepatocellular carcinoma. Int J Cancer 123: 1616-1622, 2008.

16. Ura S, Honda M, Yamashita $\mathrm{T}$, et al: Differential microRNA expression between hapatitis $\mathrm{B}$ and hepatitis $\mathrm{C}$ leading disease progression to hepatocellular carcinoma. Hepatology 49: 1098-1112, 2009.

17. Toffanin S, Hoshida Y, Lachenmayer A, et al: MicroRNA-based classification of hepatocellular carcinoma and oncogenic role of miR-517a. Gastoenterology 140: 1618-1628, 2011.

18. Yasen M,Mizushima H, Mogushi K, et al: Expression of Aurora B and alterative variant forms in hepatocellular carcinoma and adjacent tissue. Cancer Sci 100: 472-480, 2009.

19. Gramantieri L, Fornari F, Callegari E, et al: MicroRNA involvement in hepatocellular carcinoma. J Cell Mol Med 12: 2189-2204, 2008.

20. Aravalli RN, Steer CJ and Cressman NK: Molecular mechanisms of hepatocellular carcinoma. Hepatology 48: 2047-2063, 2008.

21. Ji J and Wang XW: New kids on the block. Cancer Biol Therapy 8: 1683-1690, 2009.

22. Liang L, Wong CM, Ying Q, et al: MicroRNA-125b suppressed human liver cancer cell proliferation and metastasis by directly targeting oncogene LIN28B. Hepatology 52: 1731-1740, 2010.

23. Osaki M, Takeshita F and Ochiya T: MicroRNAs as biomarkers and therapeutic drugs in human cancer. Biomarkers 13: 658-670, 2008.

24. Takamizawa J, Konishi H, Yanagisawa K, et al: Reduced expression of the let-7 micro RNAs in human lung cancers in association with shortened postoperative survival. Cancer Res 64: 3753-3756, 2004.
25. Fabbri M, Garzon R, Cimmino A, et al: MicroRNA-29 family reverts aberrant methylation in lung cancer by targeting DNA methyltransferases 3A and 3B. Proc Natl Acad Sci USA 104: 15805-15810, 2007.

26. Bommer GT, Gerin I, Feng Y, et al: p53-mediated activation of miRNA34 candidate tumor-suppressor genes. Curr Biol 17: 1298-1307, 2007.

27. Crawford M, Brawner E, Battle K, et al: MicroRNA-126 inhibits invasion in non-small cell lung carcinoma cell lines. Biochem Biophys Res Commun 373: 607-612, 2008.

28. Hayashita Y, Osada H, Tatematsu Y, et al: A polycistronic microRNA cluster, miR-17-92, is overexpressed in human lung cancers and enhances cell proliferation. Cancer Res 65: 9628-9632, 2005.

29. Volinia S, Calin GA, Liu CG, et al: A microRNA expression signature of human solid tumors defines cancer gene targets. Proc Natl Acad Sci USA 103: 2257-2261, 2006.

30. Garofalo M, Quintavalle C, Di Leva G, et al: MicroRNA signatures of TRAIL resistance in human non-small cell lung cancer. Oncogene 27: 3845-3855, 2008.

31. Yanaihara N, Caplen N, Bowman E, et al: Unique microRNA molecular profiles in lung cancer diagnosis and prognosis. Cancer Cell 9: 189-198, 2006.

32. Hu Z, Chen J, Tian T, et al: Genetic variants of miRNA sequences and non-small cell lung cancer survival. J Clin Invest 118: 2600-2608, 2008

33. Yu SL, Chen HY, Chang GC, et al: MicroRNA signature predicts survival and relapse in lung cancer. Cancer Cell 13: 48-57, 2008.

34. Markou A, Tsaroucha EG, Kaklamanis L, Fotinou M, Geogoulias V and Lianidou ES: Prognostic value of mature microRNA-21 and microRNA-205 overexpression in non-small cell lung cancer by quantitative real-time RT-PCR. Clin Chem 54: $1696-1704,2008$

35. Yan LX, Huang XF, Shao Q, et al: MicroRNA miR-21 overexpression in human breast cancer is associated with advanced clinical stage, lymph node metastasis and patient poor prognosis. RNA 14: 2348-2360, 2008

36. Chan SH, Wu CW, Li AF, Chi CW and Lin WC: miR-21 microRNA expression in human gastric carcinomas and its clinical association. Anticancer Res 28: 907-911, 2008.

37. Schepeler T, Reinert JT, Ostenfeld MS, et al: Diagnostic and prognostic microRNAs in stage II colon cancer. Cancer Res 68: 6416-6424, 2008.

38. Childs G, Fazzari M, Kung G, et al: Low-level expression of microRNAs let-7d and miR-205 are prognostic markers of head and neck squamous cell carcinoma. Am J Pathol 174: 736-745, 2009.

39. Roldo C, Missiaglia E, Hagan JP, et al: MicroRNA expression abnormalities in pancreatic endocrine and acinar tumors are associated with distinctive pathologic features and clinical behavior. J Clin Oncol 24: 4677-4684, 2006.

40. Marcucci G, Radmacher MD, Maharry K, et al: MicroRNA expression in cytogenetically normal acute myeloid leukemia. N Engl J Med 358: 1919-1928, 2008.

41. Calin GA, Ferracin M, Cimmino A, et al: A microRNA signature associated with prognosis and progression in chronic lymphocytic leukemia. N Engl J Med 353: 1793-1801, 2005.

42. Lu L, Katsaros D, de la Longrais IA, Sochirca O and Yu H: Hypermethylation of let-7a-3 in epithelial ovarian cancer is associated with low insulin-like growth factor-II expression and favorable prognosis. Cancer Res 67: 10117-10122, 2007.

43. Guo Y, Chen Z, Zhang L, et al: Distinctive microRNA profiles relating to patient survival in esophageal squamous cell carcinoma. Cancer Res 68: 26-33, 2008.

44. Chim SS, Shing TK, Hung EC, et al: Detection and characterization of placental microRNAs in material plasma. Clin Chem 54: 482-490, 2008.

45. Gilad S, Meiri E, Yogev Y, et al: Serum microRNAs are promising biomarkers. PLoS One 3: e3148, 2008.

46. Mitchel PS, Parkin RA, Kroh EM, et al: Circulating microRNAs as stable blood-based markers for cancer detection. Proc Natl Acad Sci USA 105: 10513-10518, 2008.

47. Lawrie CH, Cooper Cd, Ballabio E, Chi J, Tramonti D and Hatton CS: Aberrant expression of microRNA biosynthetic pathways components is a common feature of haematological malignancy. Br. J. Hematol 141: 672-675, 2008.

48. Diaz R, Silva J, Garcia JM, et al: Deregulated expression of miR-106a predicts survival in human colon cancer patients. Genes Chromosomes Cancer 47: 794-802, 2008. 
49. Schee K, Fodstad O and Flatmark K: MicroRNAs as biomarkers in colorectal cancer. Am J Patho 177: 1592-1599, 2010.

50. Wu WKK, Lee CW, Cho CH, Fan D, Wu K, Yu J and Sung JJY: MicroRNA dysregulation in gastric cancer: a new player enters the game. Oncogene 29: 5761-5671, 2010.

51. Zavadil J, Ye H, Liu Z, et al: Profiling and functional analyses of microRNAs and their target gene products in human uterine leiomyomas. PLoS One 5: e12362, 2010.

52. Iorio MV, Piovan $\mathrm{C}$ and Croce CM: Interplay between microRNAs and the epigenetic machinery: an intricate network. Boichim Biophys Acta 1799: 694-701, 2010.

53. Valeri N, Vannini I, Fanini F, Calore F, Adair B and Fabbri M: Epigenetics, miRNAs, and human cancer: a new chapter in human gene regulation. Mamm Genome 20: 573-580, 2009.

54. Schaefer A, Jung M, Kristiansen G, et al: MicroRNAs and cancer: current state and future perspectives in urologic oncology. Urologic Oncol 28: 4-13, 2010.

55. Garzon R, Marcucci G and Croce CM. Targeting microRNAs in cancer: rationale, strategies and challenges. Nat Rev Drug Discov 9: 775-789, 2010.

56. Calin GA, Liu CG, Sevignani C, et al: MicroRNA profiling reveals distinct signatures in B cell chronic lymphocytic leukemias. Proc Natl Acad Sci USA 101: 11755-11760, 2004.
57. Betel D, Koppal A, Angius P, Sander C and Leslie C: Comprehensive modeling of microRNA targets predicts functional non-conserved and non-canonical sites. Genome Biol 11: R90, 2010.

58. Kang JU, Koo SH, Kwon KC, Park JW and Kim JM: Gain at chromosomal region 5p15.33, containing TERT, is the most frequent genetic event in early stages of non-small cell lung cancer. Cancer Genet Cytogenet 82: 1-11, 2008.

59. Yamamoto Y, Chochi Y, Matuyama H, et al: Gain of 5p15.33 is associated with progression of bladder cancer. Oncology 72 : 132-138, 2007.

60. Yu K, Ganesan K, Tan LK, et al: A precisely regulated gene expression cassette potentially modulates metastasis and survival in multiple solid cancers. PLoS Genet 4: e1000129, 2008.

61. Bodmer D, Eleveld M, Kater-Baats E, et al: Disruption of a novel MFS transporter gene, DIRC2, by a familial renal cell carcinoma-associated $\mathrm{t}(2 ; 3)(\mathrm{q} 35 ; \mathrm{q} 21)$. Hum Mol Genet 11: 641-649, 2002.

62. Watanabe Y, Yamasaki F, Kajiwara Y, et al: Expression of phosphoprotein enriched in astrocytes $15 \mathrm{kDa}$ (PEA-15) in astrocytic tumors: a novel approach of correlating malignancy grade and prognosis. J Neurooncol 100: 449-457, 2010. 